\title{
CARACTERIZAÇÃO FENOLÓGICA FOLIAR E REPRODUTIVA DE HIRTELLA GLANDULOSA SPRENG. (CHRYSOBALANACEAE) E SUA VARIAÇÃO TEMPORAL EM AMBIENTE DE MATA CILIAR NA CHAPADA DIAMANTINA, BAHIA
}

\author{
Josevânia Carneiro de Oliveira ${ }^{1}$; Lia d' Afonsêca Pedreira de Miranda ${ }^{2}$ \\ ${ }^{1}$ Bolsista de Iniciação Cientifica, PIBIC-FAPESB, Graduanda em Ciências Biológicas, Universidade Estadual de \\ Feira de Santana. Email: vaniauefs.bio@ hotmail.com \\ 2 Orientadora do departamento de Ciências Biológicas, Universidade Estadual de Feira de Santana. Av. \\ Transnordestina, s/n, Novo Horizonte, 44036-900, Feira de Santana, BA. Email: liapmiranda@yahoo.com.br
}

PALAVRAS-CHAVE: Caracteres morfofisiológicos; sazonalidade climática; frutificação

\section{INTRODUÇÃO}

A fenologia estuda os eventos biológicos cíclicos, tais como: queda foliar, brotamento, floração e frutificação e sua correlação com os fatores ambientais (WILLIAMS-LINERA \& MEAVE, 2002). Em geral, os estudos fenológicos avaliam a influência de fatores abióticos (precipitação pluviométrica, umidade relativa do ar, temperatura, insolação e fotoperído) (FUNCH et al., 2002), fatores bióticos (relação com polinizadores, dispersores e herbívoros (BAWA et al., 2003) e, mais recentemente, tem sido avaliada a influência dos caracteres morfofuncionais das plantas (atributos foliares, potencial hídrico e trocas gasosas (MIRANDA et al. 2011; LIMA et al., 2012) nos padrões fenológicos das populações e comunidades. Todos estes fatores podem interferir nos ritmos biológicos da planta e/ou na regulação do balanço hídrico e na produção de matéria orgânica da espécie (ROSADO \& DE MATTOS, 2007).

O objetivo desse trabalho foi caracterizar o comportamento fenológico vegetativo e reprodutivo de Hirtella glandulosa, na mata ciliar do rio Lençóis e sua correlação com a variação temporal dos fatores abióticos e caracteres morfofuncionais.

\section{METODOLOGIA}

Esse trabalho assegurou a continuidade das observações fenológicas, iniciadas pela proponente em junho/2013, totalizando 36 meses de observações, ao término deste período de estudo, em maio de 2016. Os caracteres morfofuncionais (atributos foliares, potencial hídrico e clorofila), foram avaliados durante o período que correspondeu de junho de 2013 a maio de 2016, realizando as medidas sempre em períodos secos e períodos chuvosos na floresta ciliar do rio Lençóis, Bahia (12 33'34" S e 41 24'15" W). As observações fenológicas foram realizadas mensalmente durante 12 meses em 30 indivíduos, sendo observadas as fenofases: brotamento (BR), queda foliar (QD) botão (BT), flor aberta (FA), fruto imaturo (FI) e fruto maduro (FM). Na quantificação das fenofases foram utilizadas categorias de zero a quatro a intervalo de $25 \%$ entre as classes (FOURNIER, 1974). O tempo de vida foliar foi acompanhado em 20 ramos marcados e esquematizados em 5 indivíduos segundo Reich et al. (1991) adaptado por Miranda (2007). Os teores dos pigmentos foram determinados através do método indireto, utilizando-se um clorofilômetro digital (CLROROFILOG FALKER -0,1 ICF) em 02 folhas maduras (completamente expandidas), todas expostas ao sol, coletadas em quatro indivíduos. As medidas do potencial hídrico foram realizadas antes do amanhecer $\Psi_{P D}(4: 30-5: 30 \mathrm{~h})$ e depois do meio dia $\Psi_{M D}(12: 30-13: 30 \mathrm{~h})$ em 2 ramos retirados da copa de 5 indivíduos de cada ambiente, utilizando-se uma câmara de pressão de Scholander (PMS Instrument Company 1000). A amplitude diária da 
variação do potencial hídrico foi calculada através da fórmula: $\Delta \Psi=\Psi_{P D^{-}} \Psi_{M D}$. Os atributos foliares avaliados foram: espessura (ESP), massa seca da folha por unidade de área (MFA) e suculência (SUC), em 5 discos coletados em 5 folhas maduras de 4 indivíduos.

Os dados ambientais foram obtidos da estação INMET de Lençóis e o fotoperíodo do site http://aa.usno.navy.mil/data/docs/RS_OneYear.php. A relação entre as fenofases e variáveis ambientais foi avaliada por testes de correlação e os parâmetros morfofuncionais foram submetidos à análise de variância.

\section{RESULTADOS E DISCUSSÃO}

$\mathrm{Na}$ mata ciliar do rio Lençóis os eventos de queda e brotamento foliar de Hirtella glandulosa ocorreram forma contínua (Figura 1). A queda foliar foi associada negativamente com as variáveis ambientais precipitação pluviométrica e umidade relativa do ar; e o brotamento com a temperatura e o fotoperíodo (tabela 1).

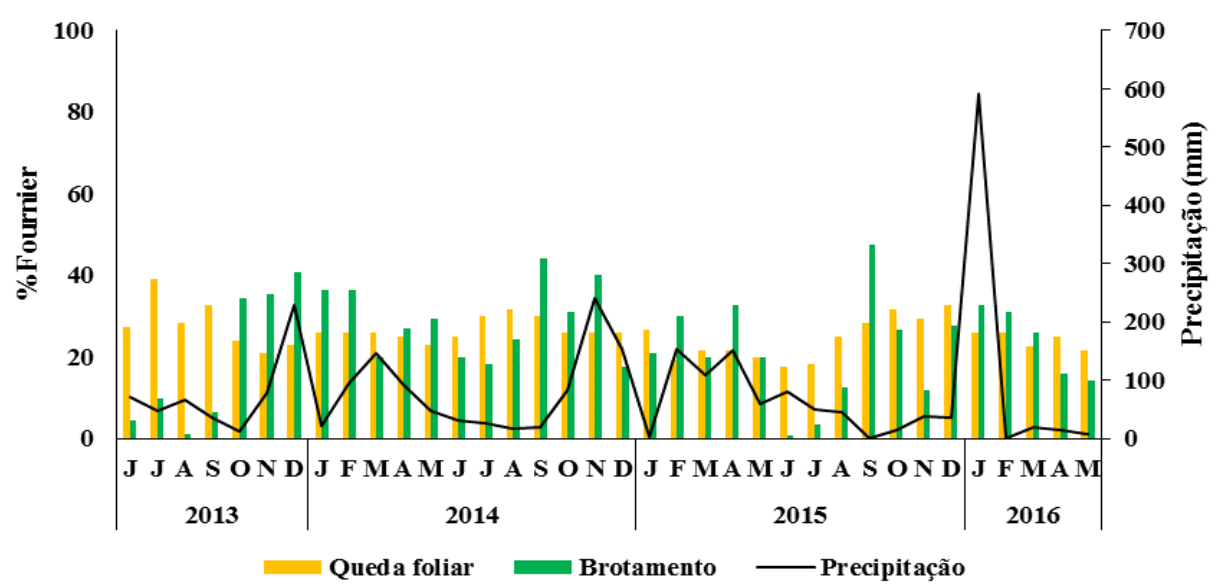

Figura 1 - Fenologia foliar de Hirtella glandulosa Spreng. e precipitação pluviométrica no período de junho/2013 a maio/2016 na Mata ciliar do rio Lençóis, Lençóis Bahia, Brasil. Dados de precipitação INMET.

Ao longo do estudo, os eventos reprodutivos foram anuais com duração intermediaria, com maior concentração de botões e flores entre outubro-dezembro, e picos de frutos (imaturos e maduros) em novembro e janeiro respectivamente (Figura 2). Quanto às fases reprodutivas, os botões florais mostraram associação negativa com a umidade relativa e positiva com o fotoperíodo e as flores abertas também com o fotoperíodo; a produção de frutos imaturos e maduros esteve associada com a precipitação, temperatura e fotoperíodo (Tabela 1).

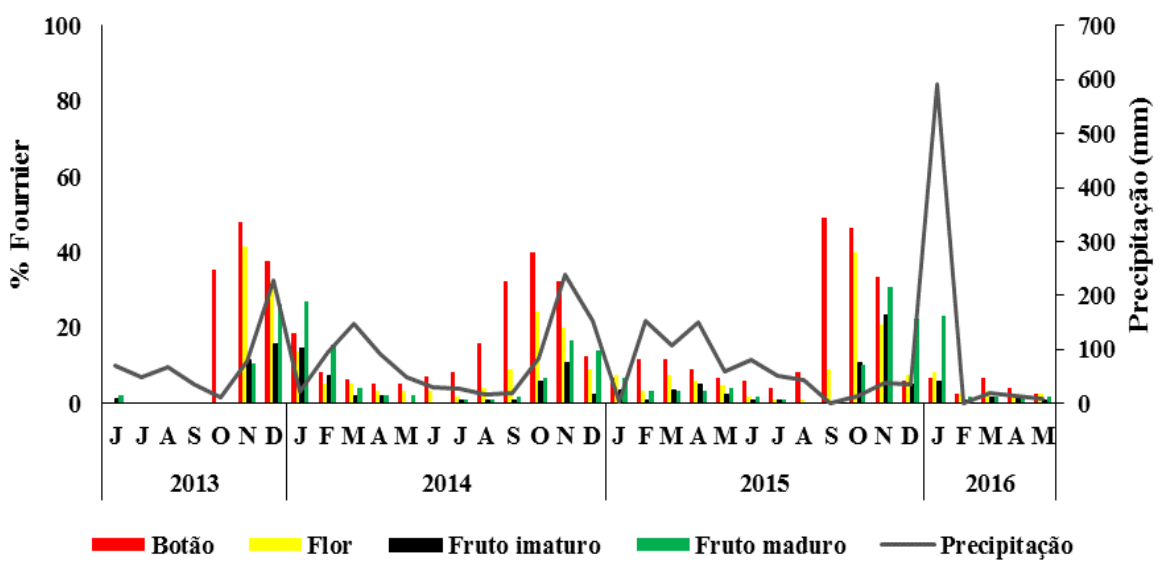

Figura 2- Fenologia reprodutiva de Hirtella glandulosa Spreng. e precipitação pluviométrica no período de junho/2013 a maio/2016 na Mata ciliar do rio Lençóis, Lençóis Bahia, Brasil. Dados de precipitação INMET. 
Tabela 1- Resultados do teste de correlação entre as variáveis ambientais e as fenofases observadas em $H$. glandulosa no período de Junho/2013 a maio/2016, na Mata Ciliar do Rio Lençóis, Chapada Diamantina, Bahia. Correlação de Pearson entre as fenofases e os preditores umidade e insolação; Correlação de Spearman entre as fenofases e os preditores precipitação, temperatura e fotoperiodo:

\begin{tabular}{cccccc}
\hline \multirow{2}{*}{ Fenofases } & $\begin{array}{c}\text { Precipitação } \\
(\mathrm{mm})\end{array}$ & $\begin{array}{c}\text { Temperatura } \\
\left(\text { média }{ }^{\circ} \mathrm{C}\right)\end{array}$ & $\begin{array}{c}\text { Umidade } \\
(\%)\end{array}$ & $\begin{array}{c}\text { Fotoperiodo } \\
(\mathrm{hh}: \mathrm{mm}: \mathrm{ss})\end{array}$ & $\begin{array}{c}\text { Insolação } \\
(\mathrm{hs})\end{array}$ \\
\cline { 2 - 6 } Queda & $-0,32^{*}$ & $-0,03$ & $-0,51^{* *}$ & 0,13 & $0,38^{*}$ \\
Brotamento & 0,06 & $0,42^{*}$ & $-0,28$ & $0,57 * *$ & 0,20 \\
Botão & 0,07 & 0,27 & $-0,32^{*}$ & $0,49 * *$ & 0,26 \\
Flor & 0,22 & $0,47^{* *}$ & $-0,20$ & $0,69^{* *}$ & 0,20 \\
Fruto Imaturo & $0,39^{*}$ & $0,52^{* *}$ & $-0,17$ & $0,67^{* *}$ & 0,11 \\
Fruto Maduro & $0,46^{* *}$ & $0,53^{* *}$ & $-0,07$ & $0,72^{* *}$ & 0,03 \\
\hline Valores significativos ${ }^{*} P<0,05 ; * *<0,0$ & & &
\end{tabular}

A queda e o brotamento foliar foram contínuos, mostrando que a espécie tem padrão perenifólio e eventos reprodutivos anuais com duração intermediaria. Uma espécie é considerada perenifólia, quando mantêm a sua copa tanto em períodos secos quanto em períodos chuvosos (BARBOSA et al., 1989) com eventos de queda e brotamento ao longo do ano. O brotamento contínuo sugere que a espécie teve a capacidade de produzir matéria orgânica que permite o desenvolvimento de novas folhas, além de ratificar a disponibilidade de água que é condição essencial para expansão celular e, por conseguinte, da própria folha (TAIZ \& ZEIGER, 2013).

As folhas marcadas para determinação da idade foliar permaneceram na copa, em média, 10,0 \pm 0,4 meses, entretanto, julgamos necessário a avaliação de maior número de folhas para a confirmação do dado.

Os teores de clorofia $a, b$ e totais foram mais elevados no período seco. $\mathrm{O}$ conteúdo de clorofilas nas folhas frequentemente é utilizado para estimar o potencial fotossintético das plantas (REGO \& POSSAMAI, 2004) e, em H. glandulosa, esteve associado ao período de maior brotamento, sugerindo que neste período a planta possa atingir taxas fotossintéticas mais elevadas para suprir a sua demanda de carbono para a produção de novas folhas. As medidas do potencial hídrico indicaram que a espécie não sofreu restrição hídrica no período de estudo. Os valores de todos os atributos foliares mostraram que praticamente não houve variação entre os períodos de avaliação. Apesar dos atributos foliares serem considerados bons descritores do comportamento ecofisiológico de diferentes espécies tropicais (ROSADO \& DE MATOS, 2007 e PEREZ-HARGUINDEGUY et al., 2013), frente as variações no ambiente, as reduzidas diferenças observadas nos caracteres morfofuncionais em $H$. glandulosa podem estar associado a regularidade da fenologia foliar ao longo de 36 meses de observação.

\section{CONSIDERAÇÕES FINAIS}

- A espécie Hirtella glandulosa tem padrão fenológico perenifólio.

- Os valores do potencial hídrico ao amanhecer são indicativos que a espécie não sofreu restrição hídrica ao longo do período de observação

- Esta espécie tem características morfofuncionais que minimizam a perda de água favorecendo a manutenção do padrão perenifólio. 


\section{REFERÊNCIAS}

1. BARBOSA, D.C.A.; ALVES, J.L.H.; PRAZERES, S.M. \& PAIVA, A.M.A. Dados fenológicos de 10 espécies arbóreas de uma área de Caatinga (Alagoinha - PE). Acta Botanica Brasílica, n. 3, p. 109-117, 1989.

2. BAWA, K.S.; Kang, H.; Grayum, M.H. Relashiopnship amosng time, frequency, and duration of flowereing in tropical rain forest. American Jounal of Botany, v. 90, n. 6, p. 877-887, 2003.

3. FOURNIER, LA. Un método cuantitativo para la medición de características fenológicas en árboles. Turrialba, v. 24, p. 22-423, 1974.

4. FUNCH, L.S.; FUNCH, R.; BARROSO, G.M. Phenology of gallery and montane forest in the Chapada Diamantina, Bahia, Brazil. Biotropica v.34, p. 40-50, 2002.

5. LIMA, Mara Rúbia de Oliveira et al. Fenologia e caracteres morfofuncionais de espécies de Miconia ruiz \& pav. (melastomataceae) em floresta ciliar, Chapada diamantina, Bahia. Dissertação do mestrado, Botânica, Universidade Estadual de Feira Santana (UEFS), 2012.

6. MIRANDA L AP, VITÓRIA AP, FUNCH LS. Leaf phenology and water potential of five arboreal species in gallery and montane forests in the Chapada Diamantina, Bahia, Brazil. Environmental and Experimental Botany, v. 70, n. 2-3, p. 143-150, 2011.

7. PÉREZ-HARGUINDEGUY, N; DÍAZ, S; GARNIER, E. New handbook for standardised measurement of plant functional traits worldwide. Australian Journal of Botany; v. 61, p. 137 - 234, 2013.

8. RÊGO, Gizelda Maia \& POSSAMAI, Edilberto. Avaliação dos Teores de Clorofila no Crescimento de Mudas do Jequitibá-Rosa (Cariniana legalis). Embrapa, Colombo, PR, Dezembro, 2004.

9. REICH PB, UHL C, WALTERS MB, ELLSWORTH DS. Leaf lifespan as a determinant of leaf structure and function among 23 tree species in Amazonian forest communities. Oecologia, v. 86, n. 1, p. 16-24, 1991.

10. ROSADO BHP, de MATTOS EA. Variação temporal de características morfológicas de folhas em dez espécies do Parque Nacional da Restinga de Jurubatiba, Macaé, RJ, Brasil. Acta Botânica Brasílica, v. 21, n. 3, p. 741-752, 2007.

11. TAIZ, Lincoln \& ZEIGER, Eduardo. Fisiologia Vegetal. Livro, 5 ed. Porto Alegre, 2013.

12. WILLIAMS-LINERA, G., MEAVE, J. Patrones fenológicos. In: Ecologia y conservación de bosques neotropicales (M. R.Guariguata \& G. H. Kattan, eds.). Libro Uníversitario Regional, p. 407-431, 2002. 